\title{
Minimally invasive fibrillating mitral valve replacement for patients with advanced cardiomyopathy: A safe and effective approach to treat a complex problem
}

\author{
Evan L. Brittain, MD, ${ }^{\mathrm{a}}$ Sandeep K. Goyal, MD, ${ }^{\mathrm{a}}$ Matthew A. Sample, MD, ${ }^{\mathrm{a}}$ Marzia Leacche, MD, \\ Tarek S. Absi, MD, ${ }^{b}$ Frank Papa, PhD, ${ }^{a}$ Keith B. Churchwell, MD, ${ }^{a}$ Stephen Ball, MD, ${ }^{b}$ \\ John G. Byrne, MD, ${ }^{\mathrm{b}}$ Simon Maltais, MD, PhD, ${ }^{\mathrm{b}}$ Michael R. Petracek, MD, ${ }^{\mathrm{b}}$ and Lisa Mendes, MD ${ }^{\mathrm{a}}$
}

\begin{abstract}
Objective: The optimal management of mitral regurgitation (MR) in patients with cardiomyopathy has been controversial. Minimally invasive fibrillating mitral valve replacement (mini-MVR) might limit postoperative morbidity and mortality by minimizing recurrent MR. We hypothesized that mini-MVR with complete chordal sparing would offer low mortality and halt left ventricular (LV) remodeling in patients with severe cardiomyopathy and severe MR.
\end{abstract}

Methods: From January 2006 to August 2009, 65 patients with an LV ejection fraction (LVEF) of $\leq 35 \%$ underwent mini-MVR. The demographic, echocardiographic, and clinical outcomes were analyzed.

\begin{abstract}
Results: The operative mortality compared with the Society of Thoracic Surgeons-predicted mortality was $6.2 \%$ versus $6.6 \%$. It was $5.6 \%$ versus $7.4 \%$ for patients with an LVEF of $\leq 20 \%$ and $8.3 \%$ versus $17.9 \%$ among patients with a Society of Thoracic Surgeons-predicted mortality of $\geq 10 \%$. At a median follow-up of 17 months, no recurrent MR or change in the LV dimensions or LVEF had developed, but the right ventricular systolic pressure had decreased $(P=.02)$. At the first postoperative visit and latest follow-up visit, the New York Heart Association class had decreased from $3.0 \pm 0.6$ to $1.7 \pm 0.7$ and $2.0 \pm 1.0$, respectively $(P<.0001$ for both). Patients with an LVEF of $\leq 20 \%$ and LV end-diastolic diameter of $\geq 6.5 \mathrm{~cm}$ were more likely to meet a composite of death, transplantation, or LV assist device insertion $(P=.046)$.
\end{abstract}

Conclusions: Our results have shown that mini-MVR is safe in patients with advanced cardiomyopathy and resulted in no recurrent MR, stabilization of the LVEF and LV dimensions, and a decrease in right ventricular systolic pressure. This mini-MVR technique can be used to address severe MR in patients with advanced cardiomyopathy. (J Thorac Cardiovasc Surg 2014;148:2045-51)

\section{Supplemental material is available online.}

The optimal treatment of patients with advanced heart failure and severe mitral regurgitation (MR) has been controversial. Up to $50 \%$ of patients with chronic heart failure will have significant MR, and worsening severity has conferred a proportional decrease in survival. ${ }^{1}$ Decreasing the severity of MR has been shown to decrease congestive heart failure symptoms and improve patients' quality of life. ${ }^{2}$ Although the benefit of preserving the

From the Division of Cardiovascular Medicine, ${ }^{a}$ Department of Medicine, and Department of Cardiac Surgery, ${ }^{\mathrm{b}}$ Vanderbilt University Medical Center, Nashville, Tenn.

Disclosures: Authors have nothing to disclose with regard to commercial support. Received for publication July 22, 2013; revisions received Sept 26, 2013; accepted for publication Oct 25, 2013; available ahead of print Dec 11, 2013.

Address for reprints: Evan L. Brittain, MD, Division of Cardiovascular Medicine, Department of Medicine, Vanderbilt University Medical Center, 1215 21st Ave S, Medical Center E, Nashville, TN 37232 (E-mail: evan.brittain@ vanderbilt.edu). $0022-5223 / \$ 36.00$

Copyright (c) 2014 by The American Association for Thoracic Surgery

http://dx.doi.org/10.1016/j.jtcvs.2013.10.062 subvalvular apparatus during mitral valve (MV) surgery has been established, the relative superiority among MV annuloplasty, repair, and replacement has remained an open question.

In early studies, MV replacement (MVR) was associated with greater surgical risk compared with MV repair. However, the surgical outcomes might be similar in high-risk populations with advanced heart failure. ${ }^{3}$ In patients with functional MR from cardiomyopathy, the recurrence of moderate or greater MR has approached $30 \%$ within 1 year after MV repair. ${ }^{4,5}$ This could explain, in part, the lack of survival benefit for patients with advanced cardiomyopathy undergoing MV repair and annuloplasty.

We have adopted a technique for MVR with anterior/posterior chordal sparing through a $5-\mathrm{cm}$ right anterolateral thoracotomy without aortic crossclamping (mini-MVR). Previous work by our group has shown that this technique is associated with low surgical mortality in patients with severe MR and a wide range of left ventricular (LV) function. ${ }^{7}$ In patients with LV dysfunction and severe MR, combining a minimally invasive approach with preservation of the subvalvular apparatus during MVR 


$\begin{array}{ll}\text { Abbreviations and Acronyms } \\ \text { LV } & =\text { left ventricular } \\ \text { LVEF } & =\text { LV ejection fraction } \\ \text { mini-MVR }= & \text { minimally invasive fibrillating mitral } \\ & \text { valve replacement } \\ \text { MR } & =\text { mitral regurgitation } \\ \text { MV } & =\text { mitral valve } \\ \text { MVA } & =\text { MV annuloplasty } \\ \text { MVR } & =\text { MV replacement } \\ \text { NYHA } & =\text { New York Heart Association } \\ \text { RV } & =\text { right ventricular } \\ \text { STS } & =\text { Society of Thoracic Surgeons }\end{array}$

might minimize adverse LV remodeling and maximize postoperative functional status. We hypothesized that this technique would be durable and offer favorable perioperative morbidity and mortality compared with the Society of Thoracic Surgeons-predicted rates in patients with an LV ejection fraction (LVEF) of $\leq 35 \%$ and advanced heart failure.

\section{METHODS \\ Study Design}

The Vanderbilt University institutional review board approved the present study (institutional review board no. 101741). From January 2006 to August 2009, 65 patients with an LVEF of $\leq 35 \%$ underwent anterior/posterior chordal sparing mini-MVR under cold fibrillatory arrest and without aortic crossclamping. All patients had symptomatic heart failure with at least moderate $(>2+)$ MR. Operative mortality was defined as death within 30 days of the surgical procedure. In-hospital mortality was defined as death during the same admission as the surgical procedure. All causes of MR were included. Patients with endocarditis, congenital disease, or concomitant mitral stenosis were excluded from the analysis.

\section{Selection Rationale}

The procedure has become our standard approach for MV surgery in patients with or without cardiomyopathy in the absence of concomitant aortic valve disease or coronary artery disease involving the left main or left anterior descending artery. This approach was also contraindicated if the aortic insufficiency were greater than moderate. For patients with concomitant coronary artery disease and mitral disease, if a lesion in the left circumflex artery or right coronary artery were amenable to percutaneous coronary intervention, we stented the coronary artery lesion and then performed minimally invasive valve surgery. For coronary artery disease involving the left main or left anterior descending artery, this approach was contraindicated.

\section{Surgical Technique}

The surgical technique has been previously described. ${ }^{7}$ In brief, after induction of general anesthesia and endotracheal intubation, a pacing Swan-Ganz pulmonary artery catheter, a transesophageal echocardiogram probe and external defibrillator (Zoll Medical Corp, Chelmsford, Mass) were placed. A $5-\mathrm{cm}$ right anterolateral thoracotomy was performed through the fourth intercostal space. If the descending aorta was free of atheroma greater than grade III, the femoral artery was cannulated using a $16 \mathrm{~F}$ or $18 \mathrm{~F}$ straight cannula (Edwards Lifesciences, Irvine, Calif). Otherwise, axillary cannulation was preferred.
The femoral vein was cannulated with a $28 \mathrm{~F}$ venous return cannula (Cardiovations, Inc, Calif), and the patients were placed on cardiopulmonary bypass with vacuum-assisted drainage. Fibrillatory arrest was induced by cooling the patients to $28^{\circ} \mathrm{C}$. The left atrium was immediately opened in the atrioventricular groove. Carbon dioxide was continuously insufflated into the chest throughout the procedure to displace the intracardiac air, and left atrial sump suction was used to maintain a clear operative field. The anterior and posterior leaflet chordae were preserved in all patients included in the present study. The anterior leaflet was divided in the middle, and the 2 created edges were reattached to the annulus, thus, reattaching all the chordal support of the anterior leaflet. Toward the end of the procedure, the patient was rewarmed, and the left atrial appendage was oversewn. Careful examination for air using transesophageal echocardiography with the patient in a deep Trendelenburg position was performed. Strict air evacuation using carbon dioxide and de-airing using a LV vent through the valve was performed before complete rewarming and defibrillation. Therefore, if the patient spontaneously cardioverted, the MV was kept incompetent to prevent air ejection. The MV was kept incompetent, and cardioversion was accomplished using the Zoll pads (Zoll Medical Corp) before completing left atrial closure.

\section{Echocardiographic Analysis}

Echocardiograms were performed at Vanderbilt University using either an iE33 (Philips, Amsterdam, The Netherlands) or Acuson (Siemens, Mountain View, Calif) cart as a part of routine clinical care. The echocardiographic data were reviewed by 2 experienced physicians (L.A.M. and K.B.C.). Quantitative analysis was performed on echocardiograms of adequate quality according to the guidelines published by the American Society of Echocardiography. ${ }^{8}$ The LV volumes were measured using the method-of-discs from the orthogonal apical views. The severity of MR was graded using the proximal isovelocity area method, vena contracta, and pulmonary vein Doppler characteristics. The right ventricular (RV) systolic pressure was estimated using the simplified Bernoulli equation according to the American Society of Echocardiography guidelines.

\section{Statistical Analysis}

Continuous data are expressed as the mean \pm standard deviation. The unpaired, 2-tailed Student $t$ test and Mann-Whitney $U$ test were used to measure differences in continuous variables between the groups according to the specifications. Categorical variables were compared between groups using the $\chi^{2}$ test. Event-free survival was defined as freedom from a combined endpoint of death, heart transplantation or transplant listing, or LV assist device insertion. Survival curves were constructed using the Kaplan-Meier method, and survival differences were compared using the log-rank test. Logistic regression analysis was used to estimate the effect of various parameters. The Society of Thoracic Surgeons (STS) estimated rates of mortality and morbidity were calculated using the online STS calculator. ${ }^{9}$ From previous work from our group, we prespecified the subgroup analysis in the high-risk group with either an LVEF of $\leq 20 \%$ or STS-predicted operative mortality of $>10 \% .{ }^{10}$ The observed and predicted mortality rates were compared using the Wilcoxon signed rank test. Statistical analyses were performed using Prism, version 5.0, software (Graph Pad Software, Inc, La Jolla, Calif) and the Statistical Package for Social Sciences, version 20, software (SPSS, Inc, Chicago, Ill).

\section{RESULTS \\ Patients}

A total of 65 patients ( $74 \%$ male, $26 \%$ female), with a mean age of $65 \pm 10$ years, underwent mini-MVR. Of the 65 patients, $6(9 \%)$ underwent concurrent tricuspid valve repair or replacement and $10(15 \%)$ 
TABLE 1. Preoperative demographics and comorbidities for entire cohort $(n=65)$

\begin{tabular}{|c|c|}
\hline Variable & Value \\
\hline Age (y) & $64.9 \pm 10.4$ \\
\hline Female gender & $17(26)$ \\
\hline \multicolumn{2}{|l|}{ Medications (\%) } \\
\hline$\beta$-Blocker & 80 \\
\hline ACEI/ARB & 74 \\
\hline MRA & 45 \\
\hline Diuretic & 86 \\
\hline Digoxin & 49 \\
\hline NYHA class & $3.0 \pm 0.6$ \\
\hline II & $12(19)$ \\
\hline III & $38(58)$ \\
\hline IV & $15(23)$ \\
\hline \multicolumn{2}{|l|}{ Rhythm (\%) } \\
\hline Sinus rhythm & 49 \\
\hline Atrial fibrillation & 22 \\
\hline Paced & 26 \\
\hline Other & 3 \\
\hline Preoperative biventricular pacing $(\%)$ & 12 \\
\hline QRS duration (ms), excluding paced patients & $115 \pm 25$ \\
\hline Brain natriuretic peptide level $(\mathrm{pg} / \mathrm{mL})(\mathrm{n}=24)$ & $935 \pm 925$ \\
\hline Creatinine $\geq 1.5 \mathrm{mg} / \mathrm{dL}$ & $13(20)$ \\
\hline Hemodialysis & $1(1.5)$ \\
\hline COPD & $19(29)$ \\
\hline Diabetes & $28(43)$ \\
\hline Hypertension & $48(74)$ \\
\hline Dyslipidemia & $19(29)$ \\
\hline Cardiogenic shock & $1(1.5)$ \\
\hline Previous CVA & $13(20)$ \\
\hline Urgent surgery & $23(35)$ \\
\hline Emergent surgery & $1(2)$ \\
\hline Concomitant CAD & $46(71)$ \\
\hline Unstable angina & $6(9.0)$ \\
\hline $\mathrm{CHF}$ & $53(82)$ \\
\hline Inotropic support & $4(6.0)$ \\
\hline Low cardiac output syndrome & $1(1.5)$ \\
\hline Preoperative right ventricular dysfunction & $16(25)$ \\
\hline Preoperative intra-aortic balloon pump use & $1(1.5)$ \\
\hline \multicolumn{2}{|l|}{ Previous cardiac operation } \\
\hline Isolated coronary artery bypass grafting & $32(49)$ \\
\hline MV surgery & $3(4.5)$ \\
\hline Other & $3(4.5)$ \\
\hline Previous percutaneous coronary intervention $(\leq 6 \mathrm{~h}$ & $10(1)$ \\
\hline
\end{tabular}

Data presented as mean \pm standard deviation, $\mathrm{n}(\%)$, or \%. ACEI, Angiotensinconverting enzyme inhibitor; $A R B$, angiotensin receptor blocker; $M R A$, mineralocorticoid receptor antagonist; NYHA, New York Heart Association; COPD, chronic obstructive pulmonary disease; $C V A$, cerebrovascular accident; $C A D$, coronary artery disease; $C H F$, congestive heart failure; $M V$, mitral valve.

underwent percutaneous coronary intervention within 6 hours of mini-MVR (hybrid revascularization). The clinical characteristics, including comorbidities, are listed in Table 1. The acuity of the study cohort was high, as evidenced by a mean preoperative New York Heart Association (NYHA) class of $3.0 \pm 0.6$ and a high prevalence of diabetes mellitus, chronic renal disease,
TABLE 2. Operative characteristics and postoperative complications

\begin{tabular}{lc}
\multicolumn{1}{c}{ Variable } & Value \\
\hline Mitral regurgitation etiology & \\
$\quad$ Ischemic & $43(66)$ \\
Functional & $10(15)$ \\
Myxomatous & $9(14)$ \\
Other & $3(5)$ \\
Prosthesis type & \\
$\quad$ Bioprosthesis & $62(95)$ \\
$\quad$ Mechanical & $3(5)$ \\
Fibrillatory arrest time (min) & $86.9 \pm 24.1$ \\
Cardiopulmonary bypass time (min) & $120.4 \pm 33.0$ \\
Operating room time (min) & $274.2 \pm 54.6$ \\
Intubation duration (h) & $17.3 \pm 19.6$ \\
Intensive care unit stay (d) & $4.3 \pm 3.7$ \\
Length of stay (d) & $8.6 \pm 4.1$ \\
Total transfusions (U) & $2.0 \pm 3.0$ \\
Postoperative low cardiac output syndrome & $5(8)$ \\
New myocardial infarction & $1(2)$ \\
Reoperation for bleeding & $2(3)$ \\
Postoperative CVA & $1(2)$ \\
Postoperative acute renal failure & $2(3)$ \\
Renal failure requiring hemodialysis & $0(0)$ \\
Postoperative TIA & $1(2)$ \\
Tracheostomy & $1(2)$ \\
New atrial fibrillation & $8(12)$ \\
Wound infection & $0(0)$ \\
Permanent pacemaker implantation & $7(11)$ \\
In-hospital mortality & $1(2)$ \\
\hline Data presented as mean \pm standard deviation or $\mathrm{n}(\%) . C V A$, & Cerebrovascular \\
accident; $T$ (IA, transient ischemic attack &
\end{tabular}

accident; TIA, transient ischemic attack.

cerebrovascular disease, and coronary artery disease. In addition, $37 \%$ of the operations were performed under urgent $(n=23)$ or emergent $(n=1)$ circumstances. Urgent status was defined as a patient presenting with heart failure requiring hospitalization and undergoing MVR in the same admission.

The operative characteristics and postoperative complications are listed in Table 2. Most patients $(81 \%)$ had secondary MR due to ischemic cardiomyopathy or dilated cardiomyopathy. The 9 patients $(14 \%)$ with myxomatous MV disease underwent MVR because the MV anatomy was not amenable to MV repair. All patients had undergone an attempt at MV repair first and were believed to require MVR after failure to reconstruct the MV competency. No perivalvular leak was found in any patient immediately postoperatively using transesophageal echocardiography. Two patients $(3 \%)$ developed postoperative renal failure, and 1 patient $(1.5 \%)$ experienced a cerebrovascular accident. The in-hospital mortality was $2.0 \%$, and the operative (30-day) mortality was $6 \%$.

The NYHA class at the first postoperative visit (median, 1.5 months; interquartile range 1.1-1.8) decreased from $3.0 \pm 0.6$ to $1.7 \pm 0.7(P<.0001)$. At the latest available follow-up (median, 40.0 months; interquartile 
TABLE 3. Echocardiographic measurements

\begin{tabular}{lccc}
\hline \multicolumn{1}{c}{ Variable } & Preoperative & Postoperative & $\begin{array}{c}\boldsymbol{P} \\
\text { value }\end{array}$ \\
\hline LVEF $(\%)(\mathrm{n}=44)$ & $\begin{array}{c}24.8 \pm 7.0 \\
\text { (range } 8-35)\end{array}$ & $25.3 \pm 13.8$ & .84 \\
& $6.4 \pm 0.9$ & $6.2 \pm 1.1$ & .19 \\
LVEDD $(\mathrm{cm})(\mathrm{n}=36)$ & $5.4 \pm 0.9$ & $5.3 \pm 1.4$ & .62 \\
LVESD $(\mathrm{cm})(\mathrm{n}=36)$ & $156.5 \pm 43.0$ & $145.5 \pm 49.7$ & .13 \\
LV mass index $\left(\mathrm{g} / \mathrm{m}^{2}\right)$ & & & \\
$\quad(\mathrm{n}=36)$ & $49.9 \pm 16.2$ & $41.7 \pm 13.7$ & .02 \\
RVSP $(\mathrm{mm} \mathrm{Hg})(\mathrm{n}=25)$ & $3.5 \pm 0.9$ & $3.4 \pm 0.7$ & .28 \\
RV size $(\mathrm{cm})(\mathrm{n}=19)$ & $5.0 \pm 0.8$ & $4.8 \pm 0.7$ & .07 \\
Left atrial size $(\mathrm{cm})$ & & &
\end{tabular}

$(\mathrm{n}=34)$

Data presented as mean \pm standard deviation. $L V E F$, Left ventricular ejection fraction; $L V E D D$, left ventricular end-diastolic dimension; $L V E S D$, left ventricular end-systolic dimension; $L V$, left ventricular; $R V S P$, right ventricular systolic pressure; $R V$, right ventricular.

range, 19.3-50.3), the NYHA class had decreased from 3.0 \pm 0.7 to $2.0 \pm 1.0(P<.0001)$.

\section{Echocardiographic Data}

The preoperative echocardiographic data are listed in Table 3. The mean preoperative LVEF was $25 \% \pm 7 \%$, and 20 patients $(31 \%)$ had an LVEF of $\leq 20 \%$. Postoperative echocardiographic data were available for a subset of 36 patients (Table 3). At a mean follow-up of $19.1 \pm 16.4$ months, no difference was found in the LVEF, LV end-diastolic diameter, LV end-systolic diameter, or LV mass index. A significant decrease occurred in the RV systolic pressure from $49.9 \pm 16.2 \mathrm{~mm} \mathrm{Hg}$ to $41.7 \pm 13.7$ $\mathrm{mm} \mathrm{Hg}(P=.02)$, with a trend found toward a decrease in the left atrial dimension $(P=.07)$. The demographic, clinical, and preoperative echocardiographic data for patients who did and did not undergo follow-up echocardiography were compared. No significant differences were found in the preoperative NYHA class, LV size or function, or RV systolic pressure (Table E1).

At a mean follow-up of 17 months, none of the 36 patients had recurrent MR graded greater than trace, and no perivalvular leaks were present. The presence of pulmonary hypertension graded moderate or greater decreased from $53 \%$ to $19 \%(P<.001)$.

\section{Mortality and Morbidity Analysis}

After a median follow-up period of 35.2 months (interquartile range, 25.5-50.3), 25 patients (36\%) met the composite endpoint of death $(\mathrm{n}=21), \mathrm{LV}$ assist device insertion, heart transplantation, or United Network for Organ Sharing listing for heart transplantation. The operative mortality $(<30$ days $)$ was $6 \%(\mathrm{n}=4)$. Four patients underwent heart transplantation or United Network for Organ Sharing listing during the study period. One patient $(1.5 \%)$ each required preoperative and intraoperative balloon pump support.

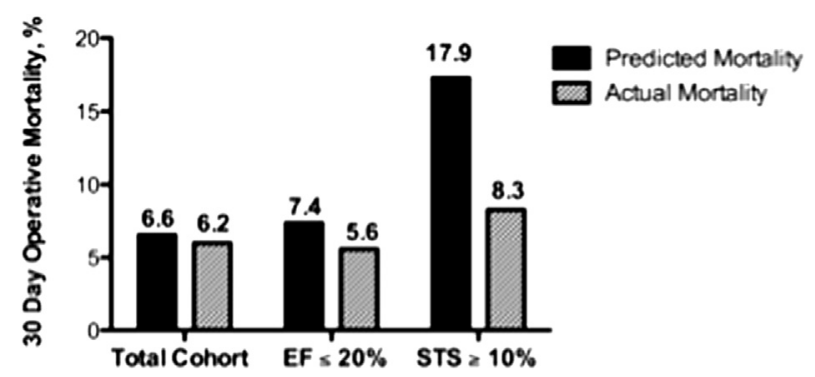

FIGURE 1. Observed versus predicted operative mortality for the entire cohort of patients, for patients with a left ventricular ejection fraction (EF) of $\leq 20 \%$ and for patients with Society of Thoracic Surgeons (STS) predicted mortality of $\geq 10 \%$. Using the Wilcoxon signed rank test, the observed operative survival was significantly better than the STS-predicted survival for the entire cohort $(P<.001)$, patients with a left ventricular EF of $\leq 20 \% \quad(P=.001)$, and patients with STS-predicted mortality of $\geq 10 \%(P=.03)$.

The observed operative mortality for the entire cohort compared with the STS-predicted mortality was $6.2 \%$ versus $6.6 \%(P<.001$; Figure 1$)$. The observed versus expected operative mortality was $5.6 \%$ versus $7.4 \%$ for patients with an LVEF of $\leq 20 \%(P=.001)$ and $8.3 \%$ versus $17.9 \%$ for patients with an STS-predicted mortality of $\geq 10 \%(P=.03)$.

The 7 patients with an LVEF of $\leq 20 \%$ and LV end-diastolic diameter of $\geq 6.5 \mathrm{~cm}$ were significantly more likely to meet the composite endpoint and thus represented a particularly high-risk group of patients for this procedure (log-rank, 0.046; Figure 2). Logistic regression analysis was used to test the effect of various factors on the composite outcome. On univariate analysis, the odds ratio for the composite outcome was 2.0 for LV end-systolic diameter $(P=.03), 5.1$ for creatinine $>1.5 \mathrm{mg} / \mathrm{dL}(P=.02), 7.7$ for NYHA class III $(P=.06)$, and 14.7 for NYHA class IV $(P=.02)$. Although the small sample size ( $\mathrm{n}=65$ patients) limited our ability to use a multivariate approach, the results yielded evidence supporting the effect of these measures on the composite outcome.

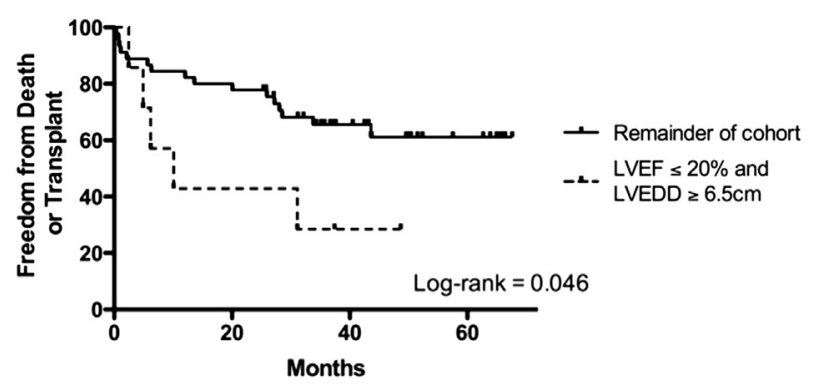

FIGURE 2. Freedom from death or transplantation in patients with a left ventricular ejection fraction of $\leq 20 \%$ and left ventricular end-diastolic diameter of $\geq 6.5 \mathrm{~cm}$. 


\section{DISCUSSION}

\section{Major Findings}

The results of our study have shown that mini-MVR with bileaflet chordal sparing using a fibrillating technique is safe and provides durable freedom from recurrent MR in patients with advanced cardiomyopathy. This approach also conferred a sustained improvement in NYHA functional class in patients with advanced cardiomyopathy. The operative mortality in our cohort was lower than that predicted by the STS risk calculator. This was especially apparent when the STS estimated risk was $\geq 10 \%$. As expected, at a mean follow-up period of 17 months, no patient had MR graded greater than trace, and no patient had a perivalvular leak. No progression of LV dilation or decrement in LVEF was found, and the stabilization of LV size and function was accompanied by a significant decrease in the RV systolic pressure, estimated using Doppler echocardiography.

\section{Surgery in Advanced Heart Failure}

The best approach to MR in patients with severe LV dysfunction is unknown. Bolling and colleagues ${ }^{11}$ published the first report of clinical and echocardiographic improvement after MV surgery in patients with advanced cardiomyopathy. They described a cohort of 16 patients undergoing MV annuloplasty (MVA) with preservation of the chordal apparatus. At 8 months of follow-up, the NYHA functional class had decreased $(3.9 \pm 0.3$ to $1.7 \pm 0.5, P<.001)$ in surviving patients, and the 1 -year survival was $75 \%$, with no operative deaths. These findings were later validated by the same group in an expanded cohort of 48 patients, although the rate of recurrent MR at follow-up was not reported. ${ }^{12}$ In a large, retrospective study, $\mathrm{Wu}$ and colleagues ${ }^{6}$ compared the outcomes between patients with MR and severe LV dysfunction who had undergone MVA (surgical management) and medical management in operative candidates. They found no survival benefit for surgical management. Recent data published by the Mayo Clinic have shown that the specifics of MV repair versus MVR did not seem to affect survival in this group of patients, and patient-associated comorbidities seemed to be the major driver of survival for this population. Another large study of patients undergoing MV surgery for ischemic MR and associated ischemic cardiomyopathy found that the reoperation rates were greater after MV repair, but the valve-related complications were similar between MVR and MV repair. ${ }^{13}$ However, they found no survival benefits between MVR and MV repair in propensity-matched populations. ${ }^{13}$

\section{Remodeling After MV Surgery in Advanced Heart Failure}

The effect of the MV surgical technique on LV remodeling is also unclear. In secondary MR from dilated cardiomyopathy, the cardiomyopathic process will persist after MV surgery, resulting in progressive LV remodeling, additional dilation of the mitral annulus, and an increase in MR. This results in a subsequent increased incidence of recurrent MR. Even with undersizing during MV repair, the posterior leaflet will be tethered, and postoperative MV competence after annuloplasty will continue to be altered. Restricting annular dilatation by MVR might, therefore, limit recurrent MR, perhaps promoting positive long-term remodeling in patients with a very low LVEF. Although MVA will eliminate or significantly reduce MR at surgery in most patients, the rate of recurrent MR has been high at medium- to long-term follow-up., ${ }^{4,14,15}$ McGee and colleagues ${ }^{5}$ found that although high-grade ( 3 or 4+) MR was uncommon immediately postoperatively, the degree of MR increased rapidly during the first 6 months and then became relatively stable. Overall, $28 \%$ of patients had grade 3 or $4+$ MR at 6 months of follow-up. Others have reported an incidence of moderate or greater MR of $29 \%$ at 3 years of follow-up after MV repair, and the degree of recurrent MR correlated with the decline in postoperative LVEF in their cohort. ${ }^{16}$ The high rates of recurrent MR after MV repair and/or MVA might have contributed to the failure of these procedures to provide a survival benefit. Therefore, MVR, which in our cohort was associated with no recurrent MR, could represent an attractive alternative to MV repair and/or MVA in this population. MVR can provide a durable solution to the treatment of secondary MR, although the initial attempts that did not preserve the chordal apparatus were associated with a postoperative decline in LV systolic function. ${ }^{17}$ However, conservation of the subvalvular apparatus during MVR has been associated with improved postoperative LVEF and a decreased LV volume. ${ }^{18}$

\section{Outcomes After MV Surgery}

Several studies have shown greater operative mortality after MVR than after MV repair. ${ }^{19-21}$ Our operative mortality and postoperative morbidity compared favorably with the STS-predicted rates and rates from recent studies comparing the outcomes after MV repair and MVR. ${ }^{19,20}$ Other recent studies have suggested that survival in high-risk populations such as ours might be similar between MVR and MV repair. ${ }^{13,15,20}$ We believe that preservation of both leaflet chordae is essential to maintaining the LV geometry and function. Moreover, avoiding aortic crossclamping and administration of cardioplegia is essential, especially in patients with an LVEF $<20 \%$ and poor RV function. Although speculative, we believe hypothermic fibrillatory arrest has proved to be a superior myocardial protection method for patients with severe LV or RV dysfunction. This technique keeps the heart decompressed by opening the left atrium immediately on fibrillation. Thus, the left ventricle will not be stressed by 
volume; the left ventricle cannot be allowed to distend, which will increase the intracardiac pressure and reduce the coronary perfusion pressure. Fibrillatory arrest has been associated with lower lactate accumulation and greater coronary flow compared with crossclamping with cardioplegic arrest and might confer added myocardial protection. ${ }^{22}$ However, Gammie and colleageus ${ }^{23}$ recently showed in a large study of less-invasive MV operations that fibrillating heart techniques were associated with a threefold greater risk of perioperative stroke. However, our group recently described a cohort of 504 patients undergoing MV surgery using the fibrillating technique, and we did not observe a significant risk of stroke. Among the highest risk patients in that study (STS-predicted mortality $\geq 10 \%)$, only 1 of $47(2 \%)$ experienced a perioperative stroke. ${ }^{10}$

The postoperative functional status is perhaps the most important metric of operative success. Mini-MVR in our cohort resulted in a significant decrease in NYHA class at both short- and intermediate-term follow-up. Studies examining NYHA functional class after MV repair have shown similar improvements in postoperative functional status. $^{12,24}$ To our knowledge, our study represents the longest follow-up NYHA functional class data of any cohort of patients with advanced heart failure after mini-MVR. Given the durability of the mini-MVR technique in eliminating MR, sustained functional class improvement might be more likely after MVR than after MV repair.

No randomized trial data exist comparing surgical versus medical management for patients with LV dysfunction and severe MR. In patients undergoing MV surgery, no randomized data have compared surgical techniques, although data from large randomized studies will be forthcoming from the Cardiothoracic Surgery Network. Our data have demonstrated that a minimally invasive fibrillating surgical approach to MVR can be performed safely, with favorable long-term outcomes with respect to functional status and LV remodeling. Our results of stabilization of LVEF and LV dimensions after chordal-sparing MVR were similar to those from earlier studies $^{25}$ and have expanded on those data by showing that this can be accomplished safely in a large cohort of patients with severe LV dysfunction.

Our cohort was too small to draw conclusions about the efficacy of this technique for the different etiologies of MV disease or compared with other techniques. However, these data warrant prospective evaluation of this technique and consideration of a randomized trial comparing this technique and conventional MV repair in patients with advanced heart failure.

\section{Study Limitations}

Our study was limited by its single-center experience and relatively small sample size; however, this is the largest cardiomyopathy cohort reported using this surgical technique. To maximize operative success, this procedure should be performed by surgeons who have had specific training in this technique. However, once this training has been obtained, it can be performed in a wide variety of clinical settings. No multivariate analysis was feasible owing to the low number of events. The decision to treat these patients surgically was made by the individual surgeon based on clinical judgment. Other patients might have been deemed nonoperative candidates, for whom we do not have outcome data. However, our cohort included patients with significant comorbidities. Only a subset of our cohort had postoperative echocardiographic data available. To address the potential for selection bias in this group, we showed that no differences were present in the preoperative functional class or echocardiographic parameters between those who did and did not undergo repeat echocardiography.

Our series did not include a control group of patients who underwent MV repair because MVR using a minimally invasive fibrillating approach was the preferred treatment of patients with severe functional and ischemic MR and advanced cardiomyopathy for whom MV surgery is indicated. We recognize this as a significant limitation of our study; however, our data suggest that mini-MVR results in no recurrent MR and outcomes similar to those of other series of high-risk patients undergoing MV repair. The use of bioprostheses was heavily favored in our cohort, given the relatively limited life expectancy of patients with advanced cardiomyopathy.

\section{CONCLUSIONS}

Our data have shown that fibrillating mini-MVR with complete chordal sparing can be performed safely in patients with advanced cardiomyopathy, with favorable results compared with the published and STS-predicted rates of operative mortality. In our cohort, this procedure resulted in no recurrent MR, stabilization of LVEF and $\mathrm{LV}$ dimensions, and a decrease in the RV systolic pressure. In addition, sustained improvement of $\geq 1$ functional class was found at 30 months of follow-up.

Future studies examining the best treatment options for patients with significant MR and LV dysfunction should consider this surgical approach as a viable treatment option.

\footnotetext{
References

1. Mehra MR, Reyes P, Benitez RM, Zimrin D, Gammie JS. Surgery for severe mitral regurgitation and left ventricular failure: what do we really know? J Card Fail. 2008;14:145-50.

2. Acker MA, Bolling S, Shemin R, Kirklin J, Oh JK, Mann DL, et al. Mitral valve surgery in heart failure: insights from the Acorn Clinical Trial. J Thorac Cardiovasc Surg. 2006;132:568-77, 77.e1-4.

3. Di Salvo TG, Acker MA, Dec GW, Byrne JG. Mitral valve surgery in advanced heart failure. J Am Coll Cardiol. 2010;55:271-82.

4. Hung J, Papakostas L, Tahta SA, Hardy BG, Bollen BA, Duran CM, et al. Mechanism of recurrent ischemic mitral regurgitation after annuloplasty: continued LV remodeling as a moving target. Circulation. 2004;110(11 Suppl 1):II85-90.
} 
5. McGee EC Jr, Gillinov AM, Blackstone EH, Rajeswaran J, Cohen G, Najam F, et al. Recurrent mitral regurgitation after annuloplasty for functional ischemic mitral regurgitation. J Thorac Cardiovasc Surg. 2004;128:916.

6. Wu AH, Aaronson KD, Bolling SF, Pagani FD, Welch K, Koelling TM. Impact of mitral valve annuloplasty on mortality risk in patients with mitral regurgitation and left ventricular systolic dysfunction. J Am Coll Cardiol. 2005;45:381-7.

7. Umakanthan R, Petracek MR, Leacche M, Solenkova NV, Eagle SS, Thompson A, et al. Minimally invasive right lateral thoracotomy without aortic cross-clamping: an attractive alternative to repeat sternotomy for reoperative mitral valve surgery. J Heart Valve Dis. 2010;19:236-43.

8. Zoghbi WA, Enriquez-Sarano M, Foster E, Grayburn PA, Kraft CD, Levine RA, et al. Recommendations for evaluation of the severity of native valvular regurgitation with two-dimensional and Doppler echocardiography. J Am Soc Echocardiogr. 2003;16:777-802.

9. Society of Thoracic Surgeons. Online STS Risk Calculator. Available at: http:// riskcalc.sts.org/STSWebRiskCalc273/. Accessed March 12, 2013.

10. Petracek MR, Leacche M, Solenkova N, Umakanthan R, Ahmad RM, Ball SK, et al. Minimally invasive mitral valve surgery expands the surgical options for high-risks patients. Ann Surg. 2011;254:606-11.

11. Bolling SF, Deeb GM, Brunsting LA, Bach DS. Early outcome of mitral valve reconstruction in patients with end-stage cardiomyopathy. J Thorac Cardiovasc Surg. 1995;109:676.

12. Bolling SF, Pagani FD, Deeb GM, Bach DS. Intermediate-term outcome of mitral reconstruction in cardiomyopathy. J Thorac Cardiovasc Surg. 1998;115:381.

13. Maltais S, Schaff HV, Daly RC, Suri RM, Dearani JA, Sundt TM III, et al. Mitral regurgitation surgery in patients with ischemic cardiomyopathy and ischemic mitral regurgitation: factors that influence survival. J Thorac Cardiovasc Surg. 2011;142:995-1001.

14. Crabtree TD, Bailey MS, Moon MR, Munfakh N, Pasque MK, Lawton JS, et al. Recurrent mitral regurgitation and risk factors for early and late mortality after mitral valve repair for functional ischemic mitral regurgitation. Ann Thorac Surg. 2008;85:1537-43.

15. Chan V, Ruel M, Mesana TG. Mitral valve replacement is a viable alternative to mitral valve repair for ischemic mitral regurgitation: a case-matched study. Ann Thorac Surg. 2011;92:1358-65; discussion 65-6.
16. Tahta SA, Oury JH, Maxwell JM, Hiro SP, Duran CM. Outcome after mitral valve repair for functional ischemic mitral regurgitation. J Heart Valve Dis. 2002;11 11-8; discussion 8-9.

17. Schuler G, Peterson KL, Johnson A, Francis G, Dennish G, Utley J, et al. Temporal response of left ventricular performance to mitral valve surgery. Circulation. 1979:59:1218-31.

18. Hennein HA, Swain J, McIntosh CL, Bonow RO, Srone CD, Clark RE Comparative assessment of chordal preservation versus chordal resection during mitral valve replacement. J Thorac Cardiovasc Surg. 1990;99:828-37.

19. Magne J, Girerd N, Sénéchal M, Mathieu P, Dagenais F, Dumesnil JG, et al Mitral repair versus replacement for ischemic mitral regurgitation comparison of short-term and long-term survival. Circulation. 2009;120(Suppl 1): S104-11.

20. Micovic S, Milacic P, Otasevic P, Tasic N, Boskovic S, Nezic D, et al Comparison of valve annuloplasty and replacement for ischemic mitral valve incompetence. Heart Surg Forum. 2008;11:E340-5.

21. Al-Radi OO, Austin PC, Tu JV, David TE, Yau TM, Bolling S. Mitral repai versus replacement for ischemic mitral regurgitation. Ann Thorac Surg. 2005; 79:1260-7.

22. Grotte GJ, Kay HR, Fallon JT, Austen WG, Buckley MJ. Effect of ventricular fibrillation and potassium induced arrest on myocardial recovery in hypothermic hearts. Surg Forum. 1980;31:296-8.

23. Gammie JS, Zhao Y, Peterson ED, O’Brien SM, Rankin JS, Griffith BP. J. Maxwell Chamberlain Memorial Paper for adult cardiac surgery: less-invasive mitral valve operations: trends and outcomes from the Society of Thoracic Surgeons Adult Cardiac Surgery Database. Ann Thorac Surg. 2010;90:1401-8 10.e1; discussion 8-10.

24. De Bonis M, Lapenna E, La Canna G, Ficarra E, Pagliaro M, Torracca L, et al Mitral valve repair for functional mitral regurgitation in end-stage dilated cardiomyopathy: role of the "edge-to-edge" technique. Circulation. 2005; 112(9 Suppl):I402-8.

25. Yun KL, Sintek CF, Miller DC, Pfeffer TA, Kochamba GS, Khonsari S, et al Randomized trial comparing partial versus complete chordal-sparing mitral valve replacement: effects on left ventricular volume and function. $J$ Thorac Cardiovasc Surg. 2002;123:707-14. 
TABLE E1. Demographics and comorbidities of cohorts with and without repeat echocardiogram

\begin{tabular}{|c|c|c|c|}
\hline \multirow[b]{2}{*}{ Variable } & \multicolumn{2}{|c|}{ Repeat echocardiogram } & \multirow[b]{2}{*}{$P$ value } \\
\hline & Yes $(n=45)$ & No $(\mathbf{n}=20)$ & \\
\hline Age (y) & $63.9 \pm 10.9$ & $67.0 \pm 9.2$ & .27 \\
\hline \multicolumn{4}{|l|}{ NYHA class } \\
\hline Preoperative & $3.0 \pm 0.7$ & $3.1 \pm 0.4$ & .56 \\
\hline First postoperative visit & $1.8 \pm 0.7$ & $1.4 \pm 0.5$ & .04 \\
\hline Latest follow-up visit & $2.1 \pm 1.0$ & $1.7 \pm 0.8$ & .92 \\
\hline Preoperative LVEF (\%) & $24.8 \pm 6.9$ & $26.3 \pm 9.8$ & .54 \\
\hline Preoperative LVEDD & $6.4 \pm 0.9$ & $6.5 \pm 1.1$ & .70 \\
\hline Preoperative LVESD & $5.4 \pm 5.6$ & $5.6 \pm 1.2$ & .60 \\
\hline Preoperative RVSP & $50.2 \pm 15.3$ & $56.3 \pm 18.1$ & .30 \\
\hline Creatinine $\geq 1.5 \mathrm{mg} / \mathrm{dL}$ & $5(11)$ & $8(40)$ & .01 \\
\hline COPD & $12(27)$ & $7(35)$ & .50 \\
\hline Diabetes & $20(44)$ & $8(40)$ & .74 \\
\hline Hypertension & $32(71)$ & $16(80)$ & .45 \\
\hline Previous CVA & $11(24)$ & $2(10)$ & .18 \\
\hline Urgent/emergent surgery & $19(42)$ & $5(25)$ & .18 \\
\hline Concomitant CAD & $29(64)$ & $17(85)$ & .09 \\
\hline $\mathrm{CHF}$ & $35(78)$ & $18(90)$ & .24 \\
\hline Preoperative RV dysfunction & $11(31)$ & $5(29)$ & .88 \\
\hline Previous cardiac surgery & $20(44)$ & $10(50)$ & .80 \\
\hline \multicolumn{4}{|c|}{$\begin{array}{l}\text { Data presented as mean } \pm \text { standard deviation or n (\%). NYHA, New York Heart } \\
\text { Association; } L V E F \text {, left ventricular ejection fraction; } L V E D D \text {, left ventricular } \\
\text { end-diastolic diameter; } L V E S D \text {, left ventricular end-systolic diameter; } R V S P \text {, right } \\
\text { ventricular systolic pressure; COPD, chronic obstructive pulmonary disease; } \\
C V A \text {, cerebrovascular accident; } C A D \text {, coronary artery disease; } C H F \text {, congestive heart } \\
\text { failure; } R V \text {, right ventricular. }\end{array}$} \\
\hline
\end{tabular}

